\title{
Editorial Board Thoughts: Events in the Life of ITAL
}

Sharon Farnel

At the end of June 2018, I will be ending my time on the ITAL Editorial Board. During my term I have had the opportunity to write several "From the Board" pieces and have very much enjoyed the freedom to explore a library technology topic of choice. This time around I would like to examine ITAL as seen through Crossref's Event Data service.

Crossref launched its Event Data service in Beta in 2017; production service was announced in late March of this year. Event Data is "an open data service that registers online activity (specifically, events) associated with Crossref metadata. Event Data will collect and store a record of any activity surrounding a research work from a defined set of web sources. The data will be made available as part of our metadata search service or via our Metadata API and normalised across a diverse set of sources. Data will be open, audit-able and replicable." ${ }^{1}$ Using DOIs as a basis, Event Data captures information on discussions, citations, references and other actions on Wikipedia, Twitter, and other services.

I thought it might be interesting to see what the Crossref Event Data might say about ITAL. I used the Event Data $\mathrm{API}^{2}$ to pull event data using the prefix for all OJS Journals hosted by Boston College (10.6017). I then used OpenRefine ${ }^{3}$ to filter out all non-ITAL records and then began further examining the data. The data was gathered on May 9, 2018.

In total, 313 events were captured. Of these, 193 events were from Wikipedia, 110 from Twitter, and 5 each from The Lens (patent citations) and Wordpress blogs. The 313 events are associated with 38 ITAL articles, the earliest from 1973 (Volume 6, Number 1, from ITAL's digitized archive), and the most recent from 2018 (Volume 37, Number 1). The greatest number of events (126) are associated with an article from Volume 25, Number 1 (2006) on RFID in Libraries. ${ }^{4}$ The other articles are associated with a varying number of discrete events, from one to 24 .

Looking more closely at the events associated with the 2006 article on RFID, all 126 events are references in Wikipedia. These represent references to the English and Japanese language Wikipedia articles on Radio Frequency Identification. Other references from Wikipedia are to articles on open access, FAST (Faceted Application of Subject Terminology), Library 2.0, Biblioteca 2.0, and others.

What about that article from 1973? It was written by J. J. Dimsdale and titled "File Structure for an On-Line Catalog of One Million Titles." The abstract provides a tantalizing glimpse into the content: "A description is given of the file organization and design of an on-line catalog suitable for automation of a library of one million books. A method of virtual hash addressing allows rapid search of the indexes to the catalog file. Storage of textual material in a compressed form allows considerable reduction in storage costs."

Sharon Farnel (sharon.farnel@ualberta.ca) is Metadata Coordinator, University of Alberta Libraries. 
There are only four events associated with this 1973 article, but interestingly all are from The Lens, ${ }^{6}$ a global patent search database. These are a set of related patents, by Mayers and Whiting, for Data Compression Apparatus and Methods. ${ }^{7}$

There are 110 events associated with Twitter, with tweets from 15 different users. The largest number of events, 21, begins with Aaron Tay, ${ }^{8}$ a librarian and blogger from Singapore Management University, tweeting about a 2016 ITAL article ${ }^{9}$ on user expectations of library discovery products, which was then retweeted 20 times. The two next most-tweeted articles $(17$ tweets/retweets each) discuss privacy and user experience in library discovery ${ }^{10}$ and "reference rot" in ETD (Electronic Theses \& Dissertations) repositories. ${ }^{11}$

What value can such a brief examination of this small set of data from a very new service provide to ITAL authors, or the Editorial Board? It can certainly provide a glimpse of who might be accessing ITAL articles, and how, and perhaps provide some hints as to ways to increase the reach of the journal. This kind of data is not a replacement for download counts or bibliographic citation patterns, but can complement them and add another layer to our understanding of the place of ITAL in the library technology community and beyond.

As ITAL continues to thrive and as services like Event Data continue to improve, I look forward to seeing what story this data continues to tell!

\section{REFERENCES}

The Event Data used for this analysis can be found at https://bit.ly/2KgDJcM.

${ }^{1}$ Madeleine Watson, "Event Data: open for your interpretation," Crossref Blog, February 25, 2016, https://www.crossref.org/blog/event-data-open-for-your-interpretation/.

${ }^{2}$ Crossref, Event Data User Guide, https://www.eventdata.crossref.org/guide/.

${ }^{3}$ OpenRefine, http://openrefine.org/.

${ }^{4}$ Jay Sing, Navjit Brar and Carmen Fong, "The State of RFID Applications in Libraries," Information Technology and Libraries 25 no. 1, 2006, https://doi.org/10.6017/ital.v25i1.3326.

${ }^{5}$ J. J. Dimsdale, "File Structure for an On-Line Catalog of One Million Titles," Information Technology and Libraries 6, no. 1, 1973, https://doi.org/10.6017/ital.v6i1.5760.

${ }^{6}$ The Lens, https://www.lens.org/.

${ }^{7}$ Clay Mayers and Douglas Whiting. Data Compression Apparatus and Method Using Matching String Searching and Huffman Encoding. US Patent 5532694, filed July 7, 1995, and issued July 2, 1996.

${ }^{8}$ Aaron Tay, https://twitter.com/aarontay.

${ }^{9}$ Irina Trapido, "Library Discovery Products: Discovering User Expectations through Failure Analysis," Information Technology and Libraries 35, no. 3, 2016, https://doi.org/10.6017/ital.v35i3.9190. 
10 Shayna Pekala, "Privacy and User Experience in 21st Century Library Discovery," Information Technology and Libraries 36, no. 2, 2017, https://doi.org/10.6017/ital.v36i2.9817.

${ }^{11}$ Mia Massicotte and Kathleen Botter, "Reference Rot in the Repository: A Case Study of Electronic Theses and Dissertations (ETDs) in an Academic Library," Information Technology and Libraries 36, no. 1, 2017, https://doi.org/10.6017/ital.v36i1.9598. 